\title{
Rapid recurrence of pulmonary hypertension following cessation of nifedipine
}

\author{
Mark M Gallagher, Ceara M Hart, Carl J Vaughan, William H Fennell
}

\begin{abstract}
Summary
In a young woman with primary pulmonary hypertension, treatment with lowdose nifedipine resulted in resolution of symptoms and of tricuspid regurgitation. On withdrawal of nifedipine, symptomatic pulmonary hypertension recurred within 48 hours and was controlled by reintroduction of low-dose nifedipine.
\end{abstract}

Keywords: primary pulmonary hypertension; nifedipine; vasodilator

Primary pulmonary hypertension is associated with a poor prognosis and although resolution has been reported, ${ }^{1}$ median survival is only 2.8 years. ${ }^{2}$ Nifedipine causes an acute reduction in pulmonary arterial pressure in most cases, but the reduction is often transient. ${ }^{3}$ In patients in whom the reduction is sustained, continuous high-dose nifedipine $(120-240 \mathrm{mg} /$ day $)$ is associated with a favourable prognosis, with $94 \%$ survival at four years. ${ }^{4}$ At these doses nifedipine commonly causes dependent oedema and postural hypotension.

\section{Case report}

A 31-year-old woman presented with recurrent syncope and progressive dyspnoea on effort. She had smoked five cigarettes daily for 10 years but stopped a year before presentation. She had never used anovulants. Physical examination was normal apart from increased intensity of the pulmonary component of the second heart sound. Electrocardiogram (ECG) revealed inversion of $T$ waves in leads $V_{1}$ to $V_{3}$ (figure 1). Chest X-ray showed prominence of the pulmonary outflow tract but isotope perfusion scan was normal.

Department of

Cardiology,

Cork University

Hospital,

Cork, Ireland

MM Gallagher

CM Hart

CJ Vaughan

WH Fennell

Correspondence to

Dr Mark M Gallagher,

Department of Cardiological

Sciences, St George's

Hospital Medical School,

Cranmer Terrace, London

SW 17 ORE, UK

Accepted 9 July 1997

Figure 1 ECG at time of presentation. In a series of four ECGs over a period of 36 hours, $T$ waves were inverted in $\mathrm{V}_{1}$ to $\mathrm{V}_{3}$ in all cases and in $\mathrm{V}_{4}$ in two cases
Transthoracic two dimensional echocardiography showed dilation and hypertrophy of the right ventricle. Doppler studies revealed moderate tricuspid regurgitation. Pulmonary artery systolic pressure was calculated at $65 \mathrm{mmHg}$ from the velocity of the regurgitant jet and the height of the jugular venous pressure. Right heart catheterisation confirmed the presence of pulmonary hypertension with a pulmonary artery pressure of $80 / 50 \mathrm{mmHg}$ and total pulmonary vascular resistance of 1106 dyne.s. $\mathrm{cm}^{-5}$ (normal 100-300). Left heart pressures, left ventriculogram and coronary angiogram were normal.

A balloon flotation catheter was used to monitor the pulmonary artery pressure for two hours after a test dose of nifedipine. Following a single oral dose of nifedipine $10 \mathrm{mg}$, pulmonary arterial pressure fell to $38 / 25 \mathrm{mmHg}$. This reduction was sustained for over two hours. The patient received slow release nifedipine (Adalat Retard) $20 \mathrm{mg}$ bid. Repeat echocardiography two days after commencement of therapy showed no evidence of tricuspid regurgitation.

During the following 10 months, exercise tolerance returned to normal and the patient was asymptomatic apart from lower limb oedema which was attributed to nifedipine. Echocardiography was repeated and no abnormality was detectable. On ECG, the T waves in $\mathrm{V}_{2}$ and $\mathrm{V}_{3}$ had reverted to normal (figure 2). Because of the oedema the patient requested that her therapy be stopped. Nifedipine was withheld and she was kept under observation.

Dyspnoea recurred within 36 hours of the last dose of slow-release nifedipine. Echocardiography was repeated 48 hours after cessation of nifedipine and showed tricuspid regurgitation with a calculated pulmonary artery systolic pressure of $70 \mathrm{mmHg}$. Nifedipine was recommenced at the previous dose and 24

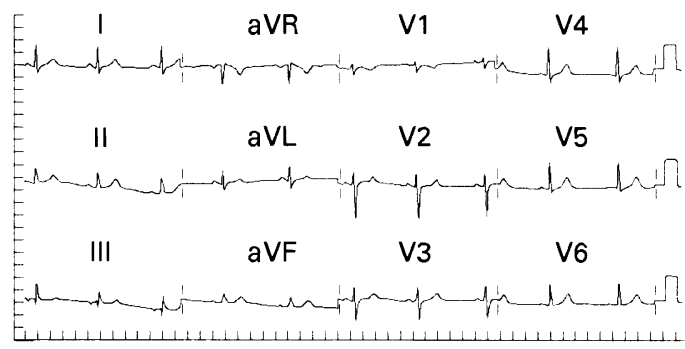

Figure 2 Following treatment with nifedipine for 10 months, the $\mathrm{T}$ waves in $\mathrm{V}_{2}$ and $\mathrm{V}_{3}$ had normalised 
hours later her symptoms had resolved. At follow-up echocardiography no tricuspid regurgitation was detectable. Measurement of pulmonary artery pressure by balloon flotation catheter was repeated after a further two months of nifedipine therapy. Over a 30-min period of observation, pressure averaged 29/18 $\mathrm{mmHg}$, with a total pulmonary vascular resistance of 375 dyne.s. $\mathrm{cm}^{-5}$. Daily dosage of nifedipine was increased to $60 \mathrm{mg}$. The patient remains well.

\section{Discussion}

It has previously been reported that pulmonary hypertension controlled with diazoxide can recur if the drug is stopped. In these cases recurrence was documented several months after withdrawal of therapy. ${ }^{56} \mathrm{~A}$ similar phenomenon has been predicted for nifedipine but never clearly documented.

In their series of patients treated with calcium channel antagonists, Rich and Brundage report the death of one patient due to right heart failure two weeks after an abrupt reduction in her daily dose of nifedipine from 160 to $40 \mathrm{mg} .{ }^{7}$ Their patient had responded well to high dose nifedipine therapy but dosage was reduced due to gastrointestinal symptoms. Because the patient was symptomatic before the dose reduction and because pulmonary artery pressure was not monitored at the time of the change the authors could only postulate that her death might have been due to rebound pulmonary hypertension secondary to nifedipine withdrawal. In a subsequent series from the same centre, it was reported that a patient who had been successfully treated with $240 \mathrm{mg}$ of nifedipine per day for four months died after therapy was stopped abruptly. No information was supplied regarding mode of death in that case.

The case which we describe differs from previously reported cases of primary pulmonary hypertension in the unusually low dose of nifedipine required to produce a favourable haemodynamic and symptomatic response. It is also the first case in which recurrence of pul-

1 Roskovec A, Montanes P, Oakley CM. Factors that influence the outcome of primary pulmonary hypertension. Br Heart f 1986;55:449-58.

2 Wood BA, Tortoledo F, Fennell WH, et al. Rapid attenuation of response to nifedipine in primary pulmonary hypertension. Chest 1982;82:793-4.

3 D'Alonzo GE, Barst RJ, Ayres SM, et al. Survival in patients with primary pulmonary hypertension. Ann Intern Med 1991;115:343-9.

4 Rich S, Kaufmann E, Levy PS. The effect of high doses of calcium channel blockers on survival in primary pulmonary hypertension. N Engl f Med 1992;327:76-81.

5 Hall DR, Petch MC. Remission of primary pulmonary

\section{Management of primary pulmonary} hypertension

- calcium channel blocking agents cause immediate dramatic fall in pulmonary artery pressure in some patients

- patients who respond acutely will usually have a good haemodynamic and functional response to calcium channel block in the long term

- prostacyclin infusion by an implanted infusion system improves symptoms in many patients who fail to respond to calcium channel blockers

- anticoagulation should be used if functional ability remains impaired

- heart-lung transplantation, or double or single lung transplant should be considered if the disease continues to progress

monary hypertension has been clearly documented following withdrawal of nifedipine. Doppler measurements correlate well with invasive measurements of pulmonary artery pressure in most patients, ${ }^{8}$ and a reasonable correlation was shown in this case. We are therefore confident that the elevated pulmonary artery pressure recorded after withdrawal of nifedipine was accurate. In the absence of tricuspid regurgitation, it is impossible to quantify pulmonary artery pressure by echocardiography. The resolution of tricuspid regurgitation suggests that pulmonary artery pressure was reduced during long-term nifedipine treatment in this case, but the extent of this reduction is unknown.

The most disturbing aspect of this case is the rapidity with which symptomatic pulmonary hypertension returned after therapy was stopped. Taken in combination with the two fatalities described by Rich's group, this raises the possibility that severe and potentially lethal rebound pulmonary hypertension can occur following abrupt withdrawal of nifedipine in this condition. We believe that patients with primary pulmonary hypertension should be cautioned not to discontinue nifedipine therapy or reduce their dosage without adequate supervision.

hypertension during treatment with diazoxide. BMF 1982; 282:1118.

6 Chan NS, McLay J, Kenmure ACF. Reversibility of primary pulmonary hypertension during six years of treatment with oral diazoxide. Br Heart $₹$ 1987;57:207-9.

7 Rich S, Brundage BH. High dose calcium channel-blocking therapy for primary pulmonary hypertension: evidence for long term reduction in pulmonary arterial pressure and regression of right ventricular hypertrophy. Circulation 1987;76:135-41

8 Brecker SJD, Gibbs JSR, Fox KM, Yacoub MH, Gibson DG. Comparison of Doppler derived haemodynamic variables and simultaneous high fidelity pressure measurements in severe pulmonary hypertension. Br Heart $f$ 1994;72:384-9. 